\title{
NOTA
}

\section{EFEITO DE LEGUMINOSAS NOS ATRIBUTOS FÍSICOS E CARBONO ORGÂNICO DE UM LUVISSOLO $^{(1)}$}

\author{
João Tavares Nascimento ${ }^{(2)}$, Ivandro de França da Silva ${ }^{(3)}$, Roberval \\ Diniz Santiago $^{(4)} \&$ Luiz de França da Silva Neto ${ }^{(5)}$
}

\begin{abstract}
RESUMO
A degradação de um solo sob cultivo é resultante, principalmente, de seu manejo inadequado, com reflexos nas baixas produtividades das culturas. Com a finalidade de avaliar o efeito de leguminosas nos atributos físicos e carbono orgânico (CO) de um Luvissolo, realizou-se, no município de Alagoinha (PB), um experimento entre 1997 e 1999, com as seguintes espécies: crotalária (Crotalaria juncea, L), guandu (Cajanus cajan,L), guandu anão (Cajanus cajan (L) Millsp), calopogônio (Calopogonium mucunoides, L), feijão-de-porco (Canavalia ensiforme, L), lab-lab (Dolichos lab lab, L), kudzu tropical (Pueraria phaseoloides, L), siratro (Macroptilium atropurpureum, L), leucena (Leucaena leucocephala, L), cunhã (Clitoria ternatea, L), mucuna preta (Styzolobium aterrimum, L), mucuna cinza (Styzolobium cinereum Piper e Tracy), e uma parcela com vegetação espontânea, como testemunha. $\mathrm{O}$ delineamento experimental utilizado foi o de blocos ao acaso em esquema de parcela subdividida, com distribuição de treze tratamentos principais na parcela (12 leguminosas +1 testemunha) e três tratamentos secundários, representados pelas profundidades de coleta de amostras de solo $(0,00-0,10 ; 0,10-0,20 ;$ e $0,20-0,30 \mathrm{~m})$, na subparcela, com três repetições. Na condição edafoclimática deste experimento, durante os três anos de trabalho, constatou-se que o emprego das leguminosas em relação à testemunha manteve inalterados o CO do solo, a densidade do solo, a porosidade total, a argila dispersa em água e a estabilidade dos agregados do solo.
\end{abstract}

Termos de indexação: adubo verde, manejo, agregação, características físicas.

\footnotetext{
(1) Trabalho Extraído da Tese de Mestrado do primeiro autor junto ao Programa de Pós-Graduação em Agronomia, Centro de Ciências Agrárias, Universidade Federal da Paraíba - UFPB. Recebido para publicação em janeiro de 2003 e aprovado em julho de 2005.

(2) Professor da Escola Agrotécnica Federal de Castanhal - EAFC. Rodovia BR 316, Km 63, CEP 68740-970 Castanhal (PA). E-mail: jtnascimenton@eafc-pa.gov.br

(3) Professor da Universidade Federal da Paraíba - UFPB. Caixa Postal 02, CEP 58397-000 Areia (PB). E-mail: ivandro@cca.ufpb.br

(4) Engenheiro-Agronômo, CCA/UFPB.

(5) Acadêmico de Agronomia, CCA/UFPB.
} 


\title{
SUMMARY: EFFECT OF LEGUMES ON THE PHYSICAL ATTRIBUTES AND ORGANIC CARBON OF AN ALFISOL
}

\begin{abstract}
Soil degradation under cultivation results mainly from the inadequate management and it reflects in low crop yields. With the purpose of evaluating the effect of legumes on physical attributes and organic carbon content of an Alfisol, an experiment was conducted in the Alagoinha County-PB, Brazil, between 1997 and 1999, with the following species: Crotalaria juncea $L$, Cajanus cajan $L$, Cajanus cajan $(L)$ Millsp, Calopogonium mucunoides $L$, Canavalia ensiforme $L$, Dolichos lab lab $L$, Pueraria phaseoloides $L$, Macroptilium atropurpureum $L$, Leucaena leucocephala $L$, Clitoria ternatea $L$, Styzolobium aterrimum $L$, Styzolobium cinereum Piper and Tracy, besides a plot with spontaneous vegetation as control treatment. A randomized split plot design was used with thirteen treatments in the main plot (12 legumes +1 control treatment) and three split-plot treatments were represented by the three soil sampling depths 0.00-0.10;0.10-0.20; and 0.20-0.30 m, with three replications. Under the experimental climate and soil conditions during the three years of study, it was observed that the cultivation of legumes in the plots did not affect the organic carbon content, density, total porosity, water-dispersible clay, and aggregate stability of the soil in comparison to the control treatment.
\end{abstract}

Index terms: green manure, management, aggregation, physical characteristics.

\section{INTRODUÇÃO}

No nordeste brasileiro, a instabilidade climática e o manejo inadequado do solo contribuem acentuadamente para degradação física, química e biológica desses solos, refletindo-se, principalmente, nas baixas produtividades das culturas. Nesta região, em decorrência de sua característica climática, a prática de agricultura de sequeiro com culturas anuais de subsistência é predominante. Esses cultivos são concentrados no único período chuvoso do ano, de fevereiro a junho, ficando, no período seco, grande parte da área abandonada, ou em pousio, servindo a resteva para o pastejo animal, e o solo sujeito à erosão, lixiviação de nutrientes e exposição à proliferação de invasoras. Há ainda o agravante de a área ser limpa com o uso de fogo no momento do novo preparo para a exploração com a lavoura.

Assim, considerando esses fatores isolados ou em conjunto, à medida que aumenta o tempo de uso desses solos, ocorrem reduções significativas do teor de matéria orgânica e de nutrientes, principalmente o $\mathrm{N}$, atribuídas, em grande parte, às perdas por erosão (Aita et al., 2001). Dessa forma, o aumento da degradação do solo torna-se visível, com a conseqüente redução de sua atividade biológica, por não ser a vegetação nativa neste período suficientemente capaz de lhe fornecer proteção eficiente contra o impacto das gotas de chuva e das altas temperaturas.

A matéria orgânica do solo é proveniente, em sua maior parte, da vegetação e seus resíduos que, em grandes quantidades e manejados adequadamente, exercem ação protetora contra a desagregação do solo pela chuva por aumentarem a formação e a estabilidade dos agregados (Carpenedo \& Mielniczuk, 1990; Silva \& Mielniczuk, 1997). A influência da matéria orgânica sobre a agregação do solo ocorre por um processo dinâmico. Ao se adicionar grande quantidade do material orgânico no solo, a atividade microbiana é intensificada, resultando em produtos (agentes cimentantes) que proporcionam a formação e estabilização de agregados (Campos et al., 1995).

Segundo Da Ros et al. (1997), os sistemas de manejo com menor revolvimento do solo e que proporcionam acúmulo de resíduos vegetais na sua superfície promovem a manutenção e a recuperação de suas características físicas. Já Nóbrega (1999) acrescenta que grandes quantidades de resíduos vegetais com relação $\mathrm{C} / \mathrm{N}$ moderada podem ajudar a estabilizar a estrutura do solo por períodos maiores, atribuindo-se esse efeito ao reforço interno dos agregados originado das secreções bacterianas. Esse fato foi constatado por Campos et al. (1995), os quais relataram que os compostos orgânicos e a ação microbiana têm atuação na estabilidade de agregados, pela alta correlação apresentada entre o conteúdo de $\mathrm{CO}$ e a atividade microbiana com o diâmetro médio geométrico dos agregados.

Os diferentes sistemas de manejo exercem também efeitos na formação e estabilização dos agregados de forma diferenciada, dependendo do tipo de cultura e do preparo de solo (Silva \& Mielniczuk, 1997). Considerando que plantas diferenciam-se entre si sobre a agregação do solo, Da Ros et al. (1997), Amado et al. (2001) e Aita et al. 
(2001) constataram que a fitomassa de leguminosas têm potencial para suprir, não só o $\mathrm{CO}$, mas também contribuir para melhorar as características físicas, químicas e biológicas do solo.

Neste sentido, sistemas de cultivo eficientes visando à diminuição do processo erosivo do solo e recuperação de suas características físicas, químicas e biológicas são buscados regionalmente, dos quais um dos promissores consiste em alternar plantas de cobertura do solo com potencial de proteção (Aita et al., 2001), com espécies para produção de grãos. Com este propósito, Amado et al. (2001) relataram que a utilização de mucuna em plantio direto de milho foi a estratégia mais eficiente em promover aumento nos estoques de $\mathrm{CO}$ e $\mathrm{N}$ total do solo. Para Tanaka (1981), os adubos verdes com leguminosas são importantes para a reciclagem de nutrientes, por produzirem grandes quantidades de fitomassa por área e por apresentarem concentrações elevadas de nutrientes na matéria seca da parte aérea, fruto da eficiência de seu sistema radicular em recuperar os nutrientes lixiviados para as camadas mais profundas do solo.

Resultados de experimentos realizados por Yaacob \& Blair (1981) demonstraram efeitos benéficos de cultivos de leguminosas nas taxas de infiltração de água e na estabilidade estrutural do solo. Para agregados maiores que $2 \mathrm{~mm}$, houve aumento de 47,3 para $61,6 \%$, graças à presença do siratro, e de 39,4 para $77,1 \%$, graças à da soja.

Dessa forma, pesquisas com espécies de leguminosas para uso nas condições edafoclimáticas do nordeste brasileiro ainda são restritas, fazendose necessário ampliá-las na busca por espécies adaptadas à região, com grande capacidade de sobrevivência nos períodos críticos e com potencial para contribuírem com maior eficácia na proteção e regeneração das características físicas, químicas e biológicas do solo.

Sendo assim, este trabalho objetivou avaliar o efeito do cultivo de espécies de leguminosas nos atributos físicos e CO de um Luvissolo de Alagoinha (PB).

\section{MATERIAL E MÉTODOS}

O ensaio foi instalado na área experimental da Empresa Estadual de Pesquisa Agropecuária da Paraíba (EMEPA-PB), localizada no município de Alagoinha/PB, em solo classificado como Luvissolo Crômico Pálico abrúptico fase floresta subcaducifólia relevo (local) suave ondulado (Embrapa, 1999), altitude de $140 \mathrm{~m}$ e declividade de $0,13 \mathrm{~m} \mathrm{~m}^{-1}$. Segundo a classificação de Köppen, o clima é do tipo As' que se caracteriza por ser quente e úmido, com precipitação média anual de $1.100 \mathrm{~mm}$, distribuída nos períodos de outono e inverno.
A área experimental foi cultivada por dez anos com culturas anuais de subsistência em sistema de rotação, e, nesse sistema, a da cana-de-açúcar permaneceu por quatro anos com preparo convencional de solo. Durante esses anos de uso, o solo não recebeu corretivo, tampouco adubação mineral.

A partir de abril de 1997, foi estabelecido o experimento com doze espécies de leguminosas, constituindo os seguintes tratamentos: guandu (Cajanus cajan, L.), guandu anão (Cajanus cajan L. Millsp), lab-lab (Dolichos lab-lab, L.), mucuna preta (Styzolobium aterrimum, L.), cunhã (Clitoria ternatea L.), calopogônio (Calopogonium mucunoides, L), mucuna cinza (Styzolobium cinereum Piper e Tracy), siratro (Macroptilium atropurpureum, L), crotalária (Crotalaria juncea, L.), feijão-de-porco (Canavalia ensiforme, L.), kudzu tropical (Pueraria phaseoloides, L.) e leucena (Leucaena leucocephala, L.). As leguminosas foram cultivadas em parcelas de $20 \mathrm{~m}^{2}(5 \times 4 \mathrm{~m})$, com espaçamento de $0,5 \mathrm{~m}$ entre fileiras e $0,25 \mathrm{~m}$ entre plantas.

No período de 1998 e 1999, houve renovação da cobertura vegetal das parcelas, sem preparo de solo, por meio de replantios das espécies, com exceção da leucena que, no ano de 1999, foi podada a $0,20 \mathrm{~m}$ do solo. A fitomassa da parte aérea proveniente das leguminosas foi roçada e deixada na superfície do solo, servindo de cobertura morta em suas respectivas parcelas. Durante o experimento, as parcelas com leguminosas foram mantidas livres de competição por meio de capina manual e não receberam adubação mineral nem corretivo. Como tratamento-testemunha, foi considerada uma parcela da área experimental mantida com vegetação espontânea.

O delineamento experimental utilizado foi o de blocos ao acaso, em esquema de parcela subdividida, distribuídos por 13 tratamentos principais na parcela (12 leguminosas +1 testemunha), e três tratamentos secundários na subparcela (profundidades do solo de $0-0,10 \mathrm{~m}, 0,10-0,20 \mathrm{~m}$ e $0,20-0,30 \mathrm{~m}$ ), com três repetições. Os dados obtidos foram submetidos à análise de variância e suas médias contrastadas pelo teste Tukey $(\mathrm{P}<0,05)$.

Para a caracterização química inicial da área experimental, o solo foi coletado por ocasião da instalação deste experimento à profundidade de $0,30 \mathrm{~m}$, que foi analisado segundo método da Embrapa (1997) e que apresentou os seguintes resultados: $\mathrm{CO}=5,35 \mathrm{~g} \mathrm{~kg}^{-1} ; \mathrm{pH}$ em $\mathrm{H}_{2} \mathrm{O}(1: 2,5)=$ 5,$8 ; \mathrm{P}=1,3 \mathrm{mg} \mathrm{dm}{ }^{-3} ; \mathrm{K}^{+}=39 \mathrm{mg} \mathrm{dm}{ }^{-3} ; \mathrm{Ca}^{2+}+\mathrm{Mg}^{2+}$ $=4,78 \mathrm{cmol}_{\mathrm{c}} \mathrm{dm}^{-3} ; \mathrm{H}+\mathrm{Al}=1,08 \mathrm{cmol}_{\mathrm{c}} \mathrm{dm}^{-3}$.

Para avaliar as características físicas e CO da área de acordo com os tratamentos adotados, foi realizada, no final do ciclo das leguminosas (novembro de 1999), outra coleta de amostras de solo. A amostra composta foi representada por três subamostras indeformadas de solo, coletadas nas 
profundidades de 0,00-0,10; de 0,10-0,20 e de 0,200,30 m. No laboratório, esse material foi manualmente destorroado e passado em peneira de 9,51 $\mathrm{mm}$ de diâmetro e, em seguida, colocado para secagem à sombra por, aproximadamente, 72 h. Após secagem, parte foi utilizada para a realização das análises físicas e parte foi destorroada e passada em peneira de $2 \mathrm{~mm}$ de diâmetro para o restante das análises.

A análise granulométrica do solo e argila dispersa em água foi realizada conforme o método descrito por Day (1965). A densidade do solo foi obtida pelo método do torrão parafinado (Blake, 1965), enquanto a densidade de partículas, pelo método descrito por Forsythe (1975). A porosidade total e o teor de CO do solo foram estimados segundo método da Embrapa (1997).

A separação e a estabilidade dos agregados em água foram obtidas, segundo o método descrito por Tisdall et al. (1978), adaptado por Carpenedo \& Mielniczuk (1990), com três repetições, nas seguintes classes de diâmetro: > 2,00, 2,00-1,00, 1,00-0,25, 0,25-0,10, 0,10-0,05 e < 0,05 mm. Na separação e distribuição do tamanho de agregados seco, utilizaram-se as mesmas classes de diâmetro acima referidas, cuja separação foi obtida mediante um conjunto de peneiras acopladas a um oscilador, funcionando durante um minuto por amostra. O material retido em cada peneira, após pesagem, foi seco em estufa a $105^{\circ} \mathrm{C}$ para obtenção da massa de solo seco (Silva \& Mielniczuk, 1997). Os agregados separados foram classificados de acordo com Edwards \& Bremner (1967): em macroagregado (diâmetro superior a $0,25 \mathrm{~mm}$ ) e microagregado (diâmetro inferior a $0,25 \mathrm{~mm}$ ), sendo distribuídos em macro e microagregado seco (MAAs, MIAs) e macro e microagregado úmido (MAAu, MIAu).

O diâmetro médio ponderado de agregados úmidos (DMPAu) e o diâmetro médio ponderado de agregados secos (DMPAs) foram obtidos mediante o cálculo do somatório dos produtos entre o diâmetro médio de cada fração de agregados e a proporção da massa da amostra, obtida por meio da divisão da massa de agregados retidos em cada peneira pela massa total da amostra com seu teor de água corrigido. $\mathrm{O}$ índice de estabilidade em água das unidades estruturais do solo foi determinado pela relação DMPAu / DMPAs (Silva \& Mielniczuk, 1997).

\section{RESULTADOS E DISCUSSÃO}

Os resultados da análise granulométrica do solo da área experimental, na profundidade de 0,000,30 m (Quadro 1), permitem classificar o solo como o da classe textural franco-arenosa (Lemos \& Santos, 1996).

Quanto ao CO do solo, foi constatada diferença significativa apenas entre profundidades. Entre seus valores médios (Quadro 2), observou-se que o da camada de $0,00-0,10 \mathrm{~m}$ foi significativamente superior ao das outras, o que evidencia uma tendência de diminuição desses valores com o aumento da profundidade no perfil do solo. Resultados semelhantes foram também evidenciados para porosidade total (PT). Em relação à densidade do solo e à argila dispersa em água, constatou-se, para ambas, diferença significativa entre profundidades (Quadro 2), sendo o valor médio da camada de 0,00-0,10 m considerado significativamente inferior para ambos os componentes, caracterizando, entre essas camadas, um acréscimo gradativo desses valores com o aumento da profundidade do solo.

Quadro 1. Composição granulométrica e classificação textural do solo do experimento na profundidade de $0,00-0,30 \mathrm{~m}$

\begin{tabular}{|c|c|c|c|}
\hline \multicolumn{3}{|c|}{ Fração granulométrica } & \multirow{2}{*}{$\begin{array}{c}\text { Classificação } \\
\text { textural }^{(1)}\end{array}$} \\
\hline Areia & Silte & Argila & \\
\hline \multicolumn{3}{|c|}{$\mathrm{g} \mathrm{kg}^{-1} \longrightarrow$} & \\
\hline 638 & 229 & 133 & Franco-arenosa \\
\hline
\end{tabular}

(1) Lemos \& Santos (1996).

Quadro 2. Valores médios de algumas características do solo em diferentes profundidades

\begin{tabular}{|c|c|c|c|c|}
\hline \multirow{2}{*}{ Profundidade } & \multicolumn{4}{|c|}{ Característica do solo } \\
\hline & $\mathrm{CO}$ & DS & $\mathbf{P T}$ & ADA \\
\hline $\mathrm{m}$ & $\mathrm{g} \mathrm{kg}^{-1}$ & $\mathrm{~g} \mathrm{~cm}^{-3}$ & $\mathrm{~m}^{3} \mathrm{~m}^{-3}$ & $\mathrm{~g} \mathrm{~kg}^{-1}$ \\
\hline $\begin{array}{l}0,00-0,10 \\
0,10-0,20 \\
0,20-0,30\end{array}$ & $\begin{array}{l}6,77 \mathrm{a} \\
6,24 \mathrm{~b} \\
5,11 \mathrm{c}\end{array}$ & $\begin{array}{l}1,41 \mathrm{~b} \\
1,47 \mathrm{a} \\
1,47 \mathrm{a}\end{array}$ & $\begin{array}{l}0,47 \mathrm{a} \\
0,45 \mathrm{~b} \\
0,45 \mathrm{~b}\end{array}$ & $\begin{array}{l}52 \mathrm{~b} \\
59 \mathrm{a} \\
65 \mathrm{a}\end{array}$ \\
\hline DMS & 0,311 & 0,023 & 0,009 & 6,31 \\
\hline
\end{tabular}

Médias seguidas pela mesma letra, na coluna, não diferem entre si ( $\mathrm{P}<0,05)$ pelo teste Tukey. CO, carbono orgânico; DS, densidade do solo; PT, porosidade total; e ADA, argila dispersa em água. 
Como mencionado, certamente a maior concentração de $\mathrm{CO}$, em combinação com a menor concentração de argila dispersa em água na camada superior do solo (0,00-0,10 m), influenciou maior agregação nesta camada e, conseqüentemente, maior porosidade total do solo (Campos et al., 1995; Nóbrega, 1999). Segundo Campos et al. (1995) e Silva \& Mielniczuk (1997), o conteúdo de CO de um solo tem relação direta com esses componentes, por influenciar suas variações. Daí, a importância no manejo das culturas, a inclusão de plantas que promovam o aumento do seu teor de carbono do solo, prática primordial responsável por sua recuperação (Da Ros et al., 1997).

Para a densidade de partículas do solo, embora constatado efeito significativo para leguminosas nas profundidades de 0,10-0,20 e 0,20-0,30 m (Quadro 3), verificou-se baixa variação entre seus valores médios nessas camadas, efeito que pode ser atribuído à variação espacial das partículas de solo.

Quanto aos agregados obtidos por peneiragem via seco, macro e microagregados (MAAs e MIAs), foram constatadas variações significativas apenas em profundidade (Quadro 4), em que a camada de 0,00-0,10 m apresentou média inferior à das outras, para a primeira variável, e efeito contrário, para a segunda variável. Nessa distribuição, destaca-se, entretanto, que as médias para as camadas de solo
Quadro 3. Valores médios da densidade de partícula (DP) dos tratamentos leguminosas e testemunha de acordo com a profundidade

\begin{tabular}{llc}
\hline & \multicolumn{2}{c}{$\mathbf{D P}\left(\mathbf{g ~ d ~ d ~}^{-3}\right)$} \\
\cline { 2 - 3 } Tratamento & $\mathbf{0 , 1 0 - 0 , 2 0 ~} \mathbf{~ m}$ & $\mathbf{0 , 2 0 - 0 , 3 0 ~} \mathbf{~}$ \\
\hline Testemunha & $2,70 \mathrm{a}$ & $2,71 \mathrm{a}$ \\
Guandu & $2,65 \mathrm{ab}$ & $2,65 \mathrm{~b}$ \\
Guandu anão & $2,64 \mathrm{~b}$ & $2,66 \mathrm{ab}$ \\
Lab-lab & $2,66 \mathrm{ab}$ & $2,63 \mathrm{~b}$ \\
Mucuna preta & $2,64 \mathrm{~b}$ & $2,66 \mathrm{ab}$ \\
Cunha & $2,65 \mathrm{ab}$ & $2,65 \mathrm{~b}$ \\
Calopogônio & $2,65 \mathrm{ab}$ & $2,66 \mathrm{ab}$ \\
Mucuna cinza & $2,65 \mathrm{ab}$ & $2,66 \mathrm{ab}$ \\
Siratro & $2,65 \mathrm{ab}$ & $2,65 \mathrm{~b}$ \\
Crotalária & $2,65 \mathrm{ab}$ & $2,66 \mathrm{ab}$ \\
Feijão-de-porco & $2,65 \mathrm{ab}$ & $2,66 \mathrm{ab}$ \\
Kudzu tropical & $2,65 \mathrm{ab}$ & $2,65 \mathrm{~b}$ \\
Leucena & $2,63 \mathrm{~b}$ & $2,65 \mathrm{~b}$ \\
DMS & 0,0575 & 0,0575 \\
\hline
\end{tabular}

$\overline{\text { Médias seguidas pela mesma letra, na coluna, não diferem entre }}$ si $(\mathrm{P}<0,05)$ pelo teste Tukey.

do MAAs foram aproximadamente duas vezes maiores em comparação com àquelas do MIAs. Estes resultados refletem a distribuição atual dos

Quadro 4. Distribuição dos valores médios das características de agregação de solo de acordo com os tratamentos

\begin{tabular}{|c|c|c|c|c|c|c|c|}
\hline \multirow{2}{*}{ Tratamento } & \multicolumn{7}{|c|}{ Característica de agregação do solo } \\
\hline & MAAs & MIAs & MAAu & MIAu & DMPAs & DMPAu & DMPAu/DMPAs \\
\hline & \multicolumn{4}{|c|}{$\%$} & \multicolumn{2}{|c|}{$\mathrm{mm} \longrightarrow$} & \\
\hline Testemunha & 67,77 & 32,23 & 22,13 & 77,87 & 2,816 & 0,473 & 0,169 \\
\hline Guandu & 67,27 & 32,73 & 17,77 & 82,23 & 2,798 & 0,351 & 0,131 \\
\hline Guandu anão & 65,87 & 34,13 & 23,93 & 76,07 & 2,709 & 0,515 & 0,195 \\
\hline Lab-lab & 64,17 & 35,83 & 20,60 & 79,40 & 2,412 & 0,315 & 0,129 \\
\hline Mucuna preta & 65,30 & 34,70 & 20,70 & 79,30 & 2,546 & 0,469 & 0,186 \\
\hline Mucuna cinza & 70,80 & 29,20 & 18,97 & 81,03 & 2,986 & 0,360 & 0,122 \\
\hline Cunhã & 65,64 & 34,36 & 19,60 & 80,40 & 2,745 & 0,416 & 0,152 \\
\hline Calopogônio & 65,80 & 34,20 & 22,80 & 77,20 & 2,652 & 0,544 & 0,207 \\
\hline Siratro & 66,47 & 33,53 & 19,57 & 80,43 & 2,686 & 0,354 & 0,133 \\
\hline Crotalária & 67,23 & 32,77 & 19,70 & 80,30 & 2,766 & 0,362 & 0,133 \\
\hline Feijão-de-porco & 66,77 & 33,23 & 18,73 & 81,27 & 2,676 & 0,352 & 0,131 \\
\hline Kudzu tropical & 70,90 & 29,10 & 21,03 & 78,97 & 2,862 & 0,407 & 0,143 \\
\hline Leucena & 64,33 & 35,67 & 20,83 & 79,17 & 2,649 & 0,400 & 0,149 \\
\hline \multicolumn{8}{|l|}{ Profundidade } \\
\hline $0,00-0,10 \mathrm{~m}$ & $64,65 \mathrm{~b}$ & $35,34 \mathrm{a}$ & $20,68^{\mathrm{ns}}$ & $79,32^{\mathrm{ns}}$ & $2,629 \mathrm{~b}$ & $0,438^{\mathrm{ns}}$ & $0,168 \mathrm{a}$ \\
\hline $0,10-0,20 \mathrm{~m}$ & $68,41 \mathrm{a}$ & $31,58 \mathrm{~b}$ & $20,70^{\text {ns }}$ & $79,30^{\mathrm{ns}}$ & $2,819 \mathrm{a}$ & $0,397^{\mathrm{ns}}$ & $0,140 \mathrm{~b}$ \\
\hline $0,20-0,30 \mathrm{~m}$ & 67,66 a & $32,33 \mathrm{~b}$ & $18,44^{\mathrm{ns}}$ & $81,56^{\mathrm{ns}}$ & $2,690 \mathrm{ab}$ & $0,392^{\mathrm{ns}}$ & $0,150 \mathrm{ab}$ \\
\hline DMS & 1,854 & 1,854 & - & - & 0,1467 & -- & 0,0235 \\
\hline
\end{tabular}

Entre profundidades, médias seguidas pela mesma letra, na coluna, não diferem entre si, e ns, não-significativo pelo teste de Tukey $(\mathrm{P}<0,05)$. MAAs, macro e MIAs microagregado seco; MAAu, macro e MIAu microagregado úmido; DMPAs, diâmetro médio ponderado de agregados secos e DMPAu, diâmetro médio ponderado de agregados úmidos. 
agregados do solo, em termos percentuais no perfil estudado. Já, para os agregados obtidos por peneiragem via úmida, macro e microagregados (MAAu e MIAu), embora não se constatando variações significativas entre tratamentos, foram observados em seus valores médios (Quadro 4) efeitos contrários aos dos macro e microagregados seco analisado anteriormente, indicando que estes sofreram grandes alterações, ou seja, alta redução e elevação, para o MAAu e MIAu, respectivamente, em virtude da fragmentação desses agregados causada pelo umedecimento.

Este aumento de microagregado úmido resultante do fracionamento de macroagregado seco, quando umedecido, reflete a alta instabilidade desses agregados e, conseqüentemente, a suscetibilidade à erosão desse solo (Tisdall \& Oades, 1982; Carpenedo \& Mielniczuk, 1990; Santiago, 1997; Pequeno, 1999). Portanto, a melhor agregação de um solo sob cultivo é aquela que apresenta baixa percentagem de microagregado e alta de macroagregado sob condições úmidas (Silva \& Mielniczuk, 1997; Pequeno, 1999). Esses efeitos foram refletidos também para o diâmetro médio ponderado de agregados, seco e úmido (DMPAs e DMPAu), quando se constatou variação significativa apenas entre profundidades para a primeira variável, a qual apresentou as camadas de $0,10-0,20 \mathrm{~m}$ e de $0,20-0,30 \mathrm{~m}$ superiores à de 0,00-0,10 m (Quadro 4).

Em relação ao índice de estabilidade de agregados em água (IE), verificou-se variação significativa apenas entre profundidades, destacando-se uma superioridade das camadas de $0,00-0,10$ e de 0,20 $030 \mathrm{~m}$, em relação à de $0,10-0,20 \mathrm{~m}$ (Quadro 4).

Segundo Silva \& Mielniczuk (1997), o índice de estabilidade de agregados em água (IE) é resultante da relação DMPAu/DMPAs e, considerando que, quanto mais este valor se aproxima de 1 mais estável é o agregado em água, os obtidos neste experimento foram considerados muito baixos e próximos entre si, notadamente refletidos pela alta redução do diâmetro dos agregados, quando submetidos ao umedecimento, o que caracteriza alta instabilidade desses agregados no perfil.

Neste estudo, sob as condições edafoclimáticas do experimento no período avaliado, os resultados indicaram baixa eficiência das leguminosas em acumular CO no solo, agravada, provavelmente, pelo alto teor de areia, baixo teor de argila e elevado grau de dispersão de argila. Estas características afetam sensivelmente o processo de formação e estabilização dos agregados do solo (Carpenedo \& Mielniczuk, 1990; Campos et al., 1995; Silva \& Mielniczuk, 1997; Nóbrega, 1999), podendo ser assim considerado este de alta vulnerabilidade ao processo erosivo.

\section{CONCLUSÕES}

1. Nas condições edafoclimáticas do experimento, no período de três anos de avaliação, as leguminosas, indistintamente, em relação à testemunha, mantiveram inalteradas as características de densidade do solo, porosidade total, argila dispersa em água e teor de CO do solo.

2. O cultivo das leguminosas não influenciou o aumento da estabilização dos agregados do solo, em relação à testemunha.

\section{LITERATURA CITADA}

AITA, C.; BASSO, C.J.; CERETTA, C.A.; GONÇALVES, C.N. \& DA ROS, C.O. Plantas de cobertura de solo como fonte de nitrogênio ao milho. R. Bras. Ci. Solo, 25:157-165, 2001.

AMADO, T.J.C.; BAYER, C.; ELTZ, F.L.F. \& BRUM, A.C.R. Potencial de culturas de cobertura em acumular carbono e nitrogênio no solo no plantio direto e a melhoria da qualidade ambiental. R. Bras. Ci. Solo, 25:189-197, 2001.

BLAKE, G.R. Bulk density. In: BLACK, C.A., ed. Methods of soil analysis. Medison, American Society of Agronomy, 1965. v.1. p.374-391.

CAMPOS, B.C.; REINERT, D.J. \& NICOLODI, R. Estabilidade estrutural de um Latossolo Vermelho-Escuro distrófico após sete anos de rotação de culturas e sistemas de manejo de solo. R. Bras. Ci. Solo, 19:121-125, 1995.

CARPENEDO, V. \& MIELNICZUK, J. Estado de agregação e qualidade de agregados de Latossolo Roxo submetidos a diferentes sistemas de manejo. R. Bras. Ci. Solo, 14:99-105, 1990.

DA ROS, C.O.; SECCO, D.; FLORIN, J.E.; PETRERE, C.; CADORE, M.A. \& PASA, L. Manejo do solo a partir de campo nativo: Efeito sobre a forma e estabilidade da estrutura ao final de cinco anos. R. Bras. Ci. Solo, 21:241$247,1997$.

DAY, P.R. Particle fractionation and particle size analysis. In: BLACK, C.A.; EVANS, D.D.; ENSMINGER, L.E.; WHITE, J.L. \& CLARK, F.E., eds. Methods of soil analysis. Madison, 1965. v.1, p.545-567.

EDWARDS, A.P. \& BREMNER, J.M. Dispersion of soil particles by sonic vibration. J. Soil Sci., 18:47-63, 1967.

EMPRESA BRASILEIRA DE PESQUISA AGROPECUÁRIA EMBRAPA. Serviço Nacional de Levantamento e Conservação do Solo. Manual de métodos de análise de solo. Rio de Janeiro, Ministério da Agricultura, 1997. 212p. 
EMPRESA BRASILEIRA DE PESQUISA AGROPECUÁRIA EMBRAPA. Centro Nacional de Pesquisa de Solos. Sistema Brasileiro de Classificação de Solos. Brasília, Produções de Informações, 1999. 412p.

FORSYTHE, W.M. Fisica de suelos: manual de laboratorio. San Jose, Instituto Interamericano de Ciencias Agricolas, 1975. 212p.

LEMOS, R.C. \& SANTOS, R.D. Manual de descrição e coleta de solo no campo. 3.ed. Campinas, Sociedade Brasileira de Ciência do Solo, 1996. 83p.

NÓBREGA, J.C.A. Adição de fosfato e de micorriza, e estabilidade de agregados em amostras de Latossolos cultivados e não cultivados. Lavras, Universidade Federal de Lavras, 1999. 64p. (Tese de Mestrado)

PEQUENO, P.L.L. Sistema radicular de leguminosas: Efeito nas propriedades físicas de um Podzólico Vermelho-Amarelo no município de Alagoinha-PB. Areia, Universidade Federal da Paraíba, 1999. 52p. (Tese de Mestrado)
SANTIAGO, R.D. Agregação do solo: Efeito de diferentes gramíneas na formação e estabilização. Areia, Universidade Federal da Paraíba, 1997. 62p. (Tese de Mestrado)

SILVA, I.F. \& MIELNICZUK, J. Avaliação do estado de agregação do solo afetado pelo uso agrícola. R. Bras. Ci. Solo, 21:313-319, 1997.

TANAKA, R.T. Adubação verde. Inf. Agropec., 7:62-67, 1981.

TISDALL, J.M.; COCKROFT, B. \& UREN, N.C. The stability of soil aggregates as affected by organic materials microbial activity and physical disruption. Aust. J. Soil Res., 16:9-17, 1978 .

TISDALL, J.M. \& OADES, J.M. Organic matter and waterstable aggregates in soils. J. Soil Sci., 33:141-163, 1982.

YAACOB, O. \& BLAIR, G.J. Effect of legume cropping and organic matter accumulation on the infiltration rate and structural stability of a granite soil under a simulated tropical environment. Plant. Soil, 60:11-20, 1981. 